\title{
Characteristics of Arterial Stiffness in Very Low Birth Weight Premature Infants
}

\author{
LAURENT TAUZIN, PASCAL ROSSI, BERNARD GIUSANO, JEAN GAUDART, ALAIN BOUSSUGES, ALAIN FRAISSE, AND \\ UMBERTO SIMEONI
}

\begin{abstract}
Division of Neonatology [L.T., U.S.], Department of Medical Information [B.G., J.G.], Pediatric Cardiology Unit [A.F.], Division of Internal Medicine and Emergency [P.R., A.B.], Assistance Publique, Hôpitaux de Marseille and Faculté de Médecine, Université de la Méditerranée, 13000 Marseille, France.
\end{abstract}

\begin{abstract}
Premature birth is a factor of increased blood pressure in adulthood. Little is known about the physiologic characteristics of the arterial bed in neonates. The aim of this study was to characterize in vivo the arterial compliance in neonates and its maturation profile in very low birth weight (VLBW) premature infants. A group of stable, VLBW premature infants was compared with a control group of near term neonates. The abdominal aortic wall distensibility coefficient (DC) and whole-body arterial compliance (WBAC) were determined using specifically designed noninvasive methods, based on ultrasonic measurements in combination with synchronous, beatto-beat recording of aortic pulse pressure (PP). On the fifth day of life, WBAC and the CD were lower in VLBW premature infants than in controls. Furthermore, WBAC and the DC remained unchanged in VLBW premature infants $7 \mathrm{wk}$ after birth. In conclusion, VLBW premature infants are characterized as early as the fifth day of life by high arterial stiffness, which persists when they reach their theoretical term. It can be speculated that early alteration of arterial elastic properties may pave the way for long-term elevation of arterial pressure in VLBW premature infants. (Pediatr Res 60: 592-596, 2006)
\end{abstract}

$\mathrm{E}$ pidemiologic and experimental studies have shown that events affecting fetal life and early infancy are linked to cardiovascular disease in adulthood. Barker et al. (1) identified a relationship between low birth weight and increased risk of arterial hypertension, carotid arteriosclerosis, and mortality by coronary heart disease or stroke in adulthood. More recently, a relationship has been shown between preterm birth and cardiovascular or metabolic disorders in adult life $(2,3)$. An inverse relationship between adult blood pressure and gestational age has been found in both adult men and women who were born prematurely $(4,5)$. Furthermore, a large epidemiologic study has reported that young male adults born extremely preterm faced an almost twofold increased risk ( $\geq 140 \mathrm{~mm} \mathrm{Hg}$ ) compared with subjects born at term (6). Last, blood pressure, pulse pressure, and vascular resistance have been reported to be increased in preterm girls after puberty (7).

Numerous animal studies based on diet restriction during pregnancy, uterine artery ligature, or antenatal exposure to

Received March 9, 2006; accepted June 14, 2006.

Correspondence: Umberto Simeoni, M.D., Department of Neonatology, La Conception University Hospital, 147 Boulevard Baille, 13385 Marseille, France; e-mail: umberto.simeoni@ap-hm.fr.

This study was supported by grant no. 2004/0421 from Assistance Publique-Hôpitaux de Marseille.

DOI: $10.1203 / 01 . p d r .0000242264 .68586 .28$ dexamethasone have shown that low birth weight is associated with increased arterial blood pressure in adulthood $(8,9)$. The mechanisms, however, are not fully known. Low birth weight has been shown to be associated with nephron number reduction and increased blood pressure in adulthood $(9,10)$. Moreover, arterial wall structure or properties may be affected, as shown by the relationship between brachial artery flowmediated dilation, endothelium-dependent response, and birth weight (11). Also, an inverse relationship has been observed between pulse wave reflections and birth weight (12). Several authors argue that in fetuses with impaired growth, elastin synthesis in the wall of the aorta and of large arteries may be deficient and may lead to permanent changes in mechanical properties $(13,14)$. Studies aimed at clarifying the relationship between arterial stiffness and low birth weight have led to similar results in children, adolescents, and adults (15-17), although it is uncertain when alteration of vascular properties may occur, i.e. during fetal life or in the postnatal period $(18,19)$. Interestingly, Akira and Yoshiyuki (18), using an echo tracking method based on ultrasound measurements of systolic and diastolic aortic diameters and cuff arterial pressure found an increased arterial stiffness in small-forgestational age compared with appropriate-for-gestational age newborn infants. However, no information is available on arterial stiffness at birth in premature, VLBW patients.

We therefore designed a noninvasive method to investigate aortic elastic properties and to characterize their maturation in neonates, including premature infants, during the first $7 \mathrm{wk}$ of life. We show that arterial stiffness is increased as early as the fifth day of life in VLBW premature infants and that this increase persists at least until the seventh week.

\section{METHODS}

Subjects. Twelve VLBW premature infants and 12 near term infants (controls) were included in a prospective, open, controlled study, after parental consent was obtained. Inclusion criteria were gestational age less than $31 \mathrm{wk}$ (group of VLBW premature infants) or ranging from 35 to $37 \mathrm{wk}$

Abbreviations: DC, distensibility coefficient; PP, pulse pressure; SV, stroke volume; VLBW, very low birth weight; WBAC, whole-body arterial compliance 
(control group), estimated by early antenatal ultrasound scans or by the date of the last menstrual period; absence of familial history of cardiovascular disease or tobacco exposure; normal fetal growth; absence of malformation syndrome; spontaneous respiration in room air, in the absence of apnea syndrome; skin temperature between 36.5 and $37.5^{\circ} \mathrm{C}$; absence of clinical and biologic signs of sepsis; clinical hemodynamic stability; and normal echocardiography with closed arterial duct on the fifth day of life.

Measurements. Measurements were performed on the fifth day of life in all patients. They were repeated on the seventh week of life in VLBW infants, before they were discharged from hospital at the time their postmenstrual age, between 35 and $37 \mathrm{wk}$, was similar to that of controls at inclusion. The study was performed in a quiet room with a stable environmental temperature $\left(25^{\circ} \mathrm{C}\right)$. All babies had been fed normally $30 \mathrm{~min}$ before the measurements and were continuously monitored for skin temperature, heart rate, and arterial oxygen saturation level.

Arterial pulse pressure. The beat-to-beat signal of the arterial blood pressure was continuously recorded by the noninvasive, photoelectric method described by Drouin et al. (20), using a Finapress (FINger Arterial PRESSure) 2300 (Ohmeda Inc.). An appropriately sized Finapress cuff was placed around the baby's wrist and an electropneumatic servosystem was placed at the level of the heart. Systolic blood pressure and diastolic blood pressure values ( $\mathrm{mm}$ $\mathrm{Hg}$ ) were obtained from a continuous tracing of arterial blood pressure, initially calibrated on brachial blood pressure recorded by oscillometric method. Measurements were recorded using a computer software (Daqware version 1.5), digitized on 12 bits using an A/D converter (PC-LPM 16) that sampled the signal at $400 \mathrm{~Hz}$, and stored the information in binary mode with the possibility of marking the events. PP was defined as systolic blood pressure minus diastolic blood pressure.

WBAC $\left(\mathrm{mm}^{3} / \mathbf{k P a} / \mathbf{m}^{2}\right)$. Arterial compliance $\left(\mathrm{mm}^{3} / \mathrm{kPa}\right)$ was estimated as described previously by Chemla et al. (21), by the formula [stroke volume $(\mathrm{SV}) / \mathrm{PP}]$, where SV is the left ventricle SV. Ultrasound measurements were performed using a Hewlett Packard SONOS 2000 duplex ultrasound scanner with a $7.5-\mathrm{MHz}$ probe coupled with electrocardiography (two electrodes on the thorax, one on the abdomen). A two-dimensional B-mode imager was used to measure the aortic valve annulus diameter by a long-axis cardiac view. The aortic annulus cross-sectional area (AoCSA) was derived from diameter $[\mathrm{d}(\mathrm{mm})]$ as follows: AoCSA $\left(\mathrm{mm}^{2}\right)=\mathrm{p} \cdot\left(\mathrm{d}^{2} / 4\right)$. Blood flow velocity signals in the ascending aorta were obtained using a suprasternal view by pulse Doppler mode. The system software measured the flow velocity integral automatically, avoiding the need for tracing over the wave form by hand. SV was obtained by the usual product of flow velocity integral and AoCSA. SV and PP were recorded simultaneously from an average of five consecutive cardiac cycles. To eliminate factors associated with neonatal development of arterial tree, SV/PP was index-linked to the body surface area.

$\mathrm{DC}$ of the abdominal aorta $\left(10^{-6} / \mathrm{kPa}\right)$. Transversal, ultrasonic B-mode (7.5-MHz transducer) images of the abdominal aorta were obtained in the supraceliac region, using a transverse subcostal view. The simultaneous measurement of arterial blood pressure and of cross-sectional areas of abdominal aorta served to determine the DC when the vessel diameter was larger than $3 \mathrm{~mm}$ according to Reneman and Hoeks (22). DC was derived from the systolic-diastolic variation coefficient of the abdominal aorta area, and the simultaneous measure of PP, using the following formula: DC $=[$ (A syst A diast)/A diast]/PP, where A syst is the abdominal aorta cross-sectional area at end systole and A diast is the cross-sectional area at end diastole. The end diastolic frame was selected at the peak of the $\mathrm{R}$ wave on the simultaneous ECG recording, and the end-systolic frame was defined as the largest vascular surface during the last half of the $\mathrm{T}$ wave. The systolic and diastolic artery cross-sectional areas were determined manually using five consecutive cardiac cycles.

Ethics. Study protocol was approved by the local ethics committee (Comité Consultatif de Protection des Personnes dans la Recherche Biomédicale de Marseille No. 2). Research was conducted according to the Good Clinical Practice guidelines developed by the International Conference on Harmonization.

Data analysis. Data are expressed as mean \pm standard deviation (SD). Three series of measurements were obtained (premature infants on d 5, premature infants at $7 \mathrm{wk}$, and controls on $\mathrm{d} 5$ ). A $t$ test for paired or unpaired data were used for normally distributed data. Nonparametric Wilcoxon and Mann-Whitney $U$ tests were used, respectively, for paired and unpaired data when distribution was not normal; $p$ values $<0.05$ were considered significant. The relationships between DC and infants characteristics at the same postmenstrual age were investigated using regression linear models.

Intraoperator variability. To assess variability of arterial compliance and DC measures, 25 explorations were performed that included two intrasession measurements by a single operator. The Bland-Altman comparison analysis is mainly a tool for clinical interpretation and can be used to check the repeatability of a measurement technique within the same subject (23).
According to this method, the difference between both measurements was plotted against their mean for each subject; $95 \%$ of differences were expected to be $<2$ SDs. The bias, defined as the mean of differences, was $4.10^{-6} / \mathrm{kPa}$ for DC and $0.016 \mathrm{~mm}^{3} / \mathrm{kPa}$ for arterial compliance; agreement limits, defined as bias $\pm 1.96 \mathrm{SD}$, were 42 to $3410^{-6} / \mathrm{kPa}$ and 0.4 to $-0.37 \mathrm{~mm}^{3} / \mathrm{kPa}$, respectively (Figs. 1 and 2). The precision coefficient, defined as the mean of absolute values of differences was $15.310^{-6} / \mathrm{kPa}$ for DC and $0.15 \mathrm{~mm}^{3} / \mathrm{kPa}$ for arterial compliance. The bias of both methods was thus close to zero, and the precision coefficients gave reliable results for clinical significance.

\section{RESULTS}

Subjects. Two subjects were excluded from the study: one VLBW premature infant because of repeated agitation and one control patient because of abdominal distention. Gestational age of patients included in the study group was $28.6 \pm 0.6 \mathrm{wk}$ compared with $35.5 \pm 0.8 \mathrm{wk}$ in the control group. Sex ratios were similar in both groups. The causes of preterm birth in the study group were maternal bleeding in four cases, fetal heart rate alterations in one, and premature rupture of membranes or preterm labor in six. Nine VLBW premature infants had received one course of antenatal betamethasone to accelerate fetal pulmonary maturation, and none of the VLBW premature infant received postnatal steroids. Postnatal growth of VLBW premature infants allowed them to reach weights and body surface areas comparable with those of controls at a similar postmenstrual age. No patient was receiving oxygen therapy at the time of the measurements. The cross-sectional area of the abdominal aorta tended to be lower in VLBW premature infants than in controls at the same postmenstrual age $\left(19 \mathrm{~mm}^{2}\right.$ versus $23 \mathrm{~mm}^{2}$ and $14 \mathrm{~mm}^{2}$ versus $16 \mathrm{~mm}^{2}$ at end systole and end diastole, respectively). The aortic annulus cross-sectional area was similar in VLBW infants and in controls at a comparable postmenstrual age. Table 1 shows general and anatomic characteristics of the subjects.

Hemodynamic and arterial stiffness measurements. All measurements were performed after making sure that hemodynamic and anatomic echocardiographic characteristics were normal and in the absence of a patent ductus arteriosus. Heart rate was higher in VLBW premature infants on d 5 than in controls and remained unchanged at $7 \mathrm{wk}$ of life. SV was lower in VLBW premature infants on $\mathrm{d} 5$ than in controls and increased at $7 \mathrm{wk}$. Systolic and diastolic blood pressures were

Distensibility coefficient

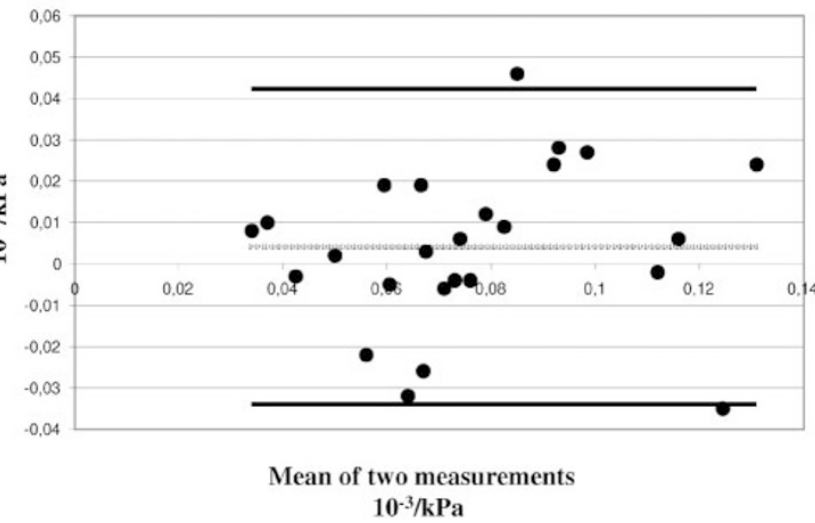

Figure 1. Repeatability of the abdominal aorta DC. Bias (shaded line); superior and inferior agreement limits (solid line). 
Total arterial compliance

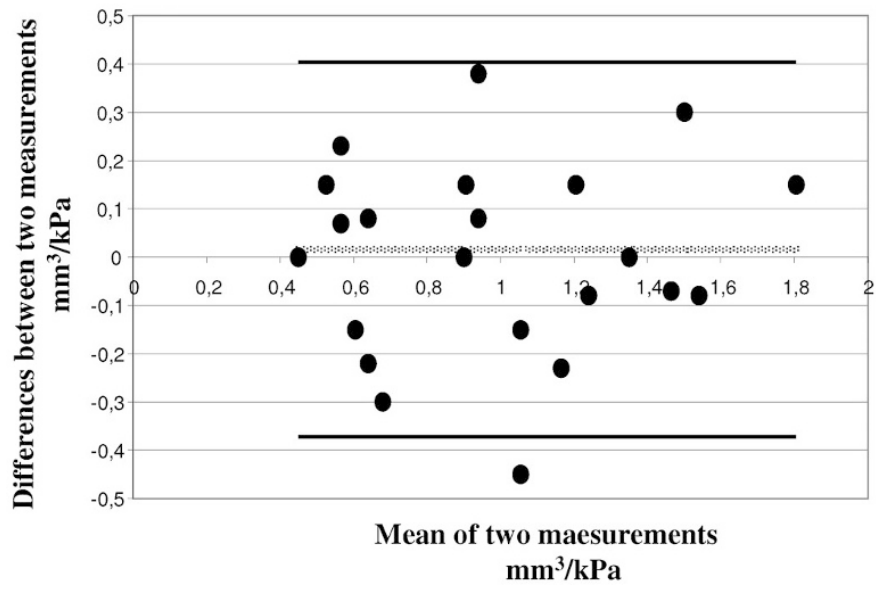

Figure 2. Repeatability of total arterial compliance. Bias (shaded line); superior and inferior agreement limits (solid line).

not different in VLBW premature infants on $\mathrm{d} 5$ and at $7 \mathrm{wk}$ and in controls. PP was higher in VLBW premature infants on $\mathrm{d} 5$ than in controls and remained unchanged at $7 \mathrm{wk}$ (Table 2).

Both DC and WBAC were considerably decreased (by $51 \%$ and $37 \%$, respectively) in WLBW premature infants on d 5 compared with controls. Interestingly, they remained lower at $7 \mathrm{wk}$ (41\% and 32\%, respectively) (Table 2, Figs. 3 and 4). By use of regression linear models, although depending on the study group, DC was independent on postmenstrual age, sex, weight, or heart rate (Table 3).

\section{DISCUSSION}

This study provides the first descriptive data on WBAC and abdominal aortic stiffness in VLBW premature infants and shows that arterial stiffness is increased as early as the 5th day of life and remains increased when VLBW premature infants approach their theoretical term.

Validity of such findings is based on PP measurements and on two different, complementary approaches of arterial compliance that have been validated in adults: WBAC, adapted from the method of Chemla et al. (21), and measurement of

Table 1. Characteristics of patients

\begin{tabular}{|c|c|c|c|}
\hline & $\begin{array}{c}\text { PIs d } 5 \\
(n=11)\end{array}$ & $\begin{array}{l}\text { PIs } 7 \text { wk } \\
(n=11)\end{array}$ & $\begin{array}{l}\text { Controls } \\
(n=11)\end{array}$ \\
\hline Maternal age, y & $28 \pm 2$ & - & $31 \pm 2$ \\
\hline Primipara, no. & 3 & - & 3 \\
\hline Cesarean section, no. & 9 & - & 8 \\
\hline Postmenstrual age, wk & $28.6 \pm 0.6^{*}$ & $35.9 \pm 0.8$ & $35.5 \pm 0.8$ \\
\hline Boy, no. & $7 / 11$ & - & $7 / 11$ \\
\hline Weight, $g$ & $1091 \pm 167 *$ & $2178 \pm 254$ & $2360 \pm 263$ \\
\hline Body surface area, $\mathrm{m}^{2}$ & $0.12 \pm 0.01 *$ & $0.17 \pm 0.01$ & $0.17 \pm 0.01$ \\
\hline Height, $\mathrm{cm}$ & $37 \pm 0.7^{*}$ & $45 \pm 0.5$ & $46 \pm 0.7$ \\
\hline AoCSA, mm² & $23 \pm 4^{*}$ & $33 \pm 7$ & $34 \pm 4$ \\
\hline A syst, $\mathrm{mm}^{2}$ & $12 \pm 2 *$ & $19 \pm 3$ & $23 \pm 5$ \\
\hline A diast, $\mathrm{mm}^{2}$ & $10 \pm 2 *$ & $14 \pm 3$ & $16 \pm 3$ \\
\hline
\end{tabular}

Data are expressed as mean $\pm \mathrm{SD}$ or as number of subjects.

$* p<0.001$ vs controls.

PIs, VLBW premature infants.
Table 2. Hemodynamic measurements and changes in arterial stiffness

\begin{tabular}{lccc}
\hline & $\begin{array}{c}\text { PIs d 5 } \\
(n=11)\end{array}$ & $\begin{array}{c}\text { PIs 7 wk } \\
(n=11)\end{array}$ & $\begin{array}{c}\text { Controls } \\
(n=11)\end{array}$ \\
\hline Heart rate, bpm & $153.0 \pm 10.0^{*}$ & $150.0 \pm 14.0^{*}$ & $132.0 \pm 17.0$ \\
Stroke volume, $\mathrm{mL}$ & $2.1 \pm 0.40 \dagger$ & $3.6 \pm 1.2$ & $3.5 \pm 0.6$ \\
Systolic blood pressure, $\mathrm{mm} \mathrm{Hg}$ & $69.0 \pm 20.0$ & $63.0 \pm 8.0$ & $61.0 \pm 14.0$ \\
Diastolic blood pressure, mm Hg & $39.0 \pm 14.0$ & $33.0 \pm 5.0$ & $42.0 \pm 15.0$ \\
Pulse pressure, mm Hg & $30.0 \pm 8.0^{*}$ & $30.0 \pm 6.0 \dagger$ & $19.0 \pm 4.4$ \\
WBAC, $\mathrm{mm}^{3} / \mathrm{kPa} / \mathrm{m}^{2}$ & $4.9 \pm 1.3^{*}$ & $5.3 \pm 1.5^{*}$ & $7.8 \pm 2.0$ \\
$\mathrm{DC}, 10^{-6} / \mathrm{kPa}$ & $70.9 \pm 18.3 \dagger$ & $90.1 \pm 39.1^{*} 154.2 \pm 39.6$
\end{tabular}

Data are expressed as mean \pm SD or as number of subjects.

$* p<0.01$ vs controls; $\dagger p<0.001$ vs controls.

PIs, VLBW premature infants.

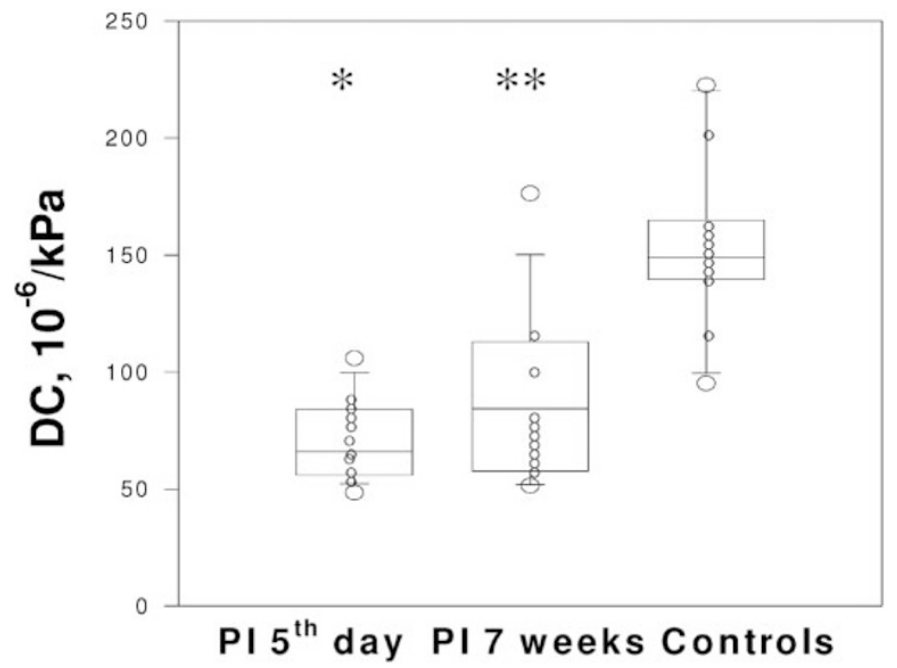

Figure 3. Comparison of WBAC in VLBW premature infants and in controls. $* p<0.002$; PI on fifth day $v s$ controls. $* * p<0.005$, PI at 7 wk $v s$ controls.

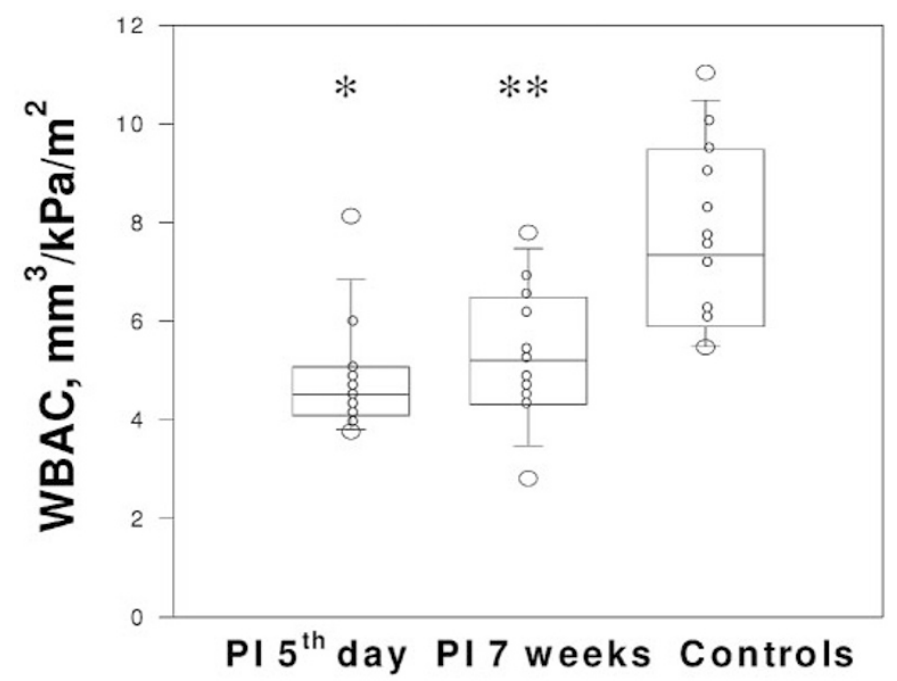

Figure 4. Comparison of abdominal aorta distensibility coefficient in VLBW premature infants and in controls. $* p<0.001$, PI on the 5th day $v s$ controls. ** $p<0.005$, PI at 7 wk $v s$ controls.

the abdominal aorta DC by high-resolution B-mode ultrasonography, adapted from Reneman and Hoeks (22). The methods used allowed synchronous, beat-to-beat recording of Finapress wrist pressure and ultrasonographic measurements 
Table 3. Factors related to DC using regression linear models

\begin{tabular}{lcc}
\hline Regression factor & $\begin{array}{c}\text { Regression } \\
\text { coefficient }\end{array}$ & $p$ \\
\hline Group & -0.36 & 0.003 \\
Sex & -0.02 & 0.089 \\
Weight & 0.001 & 0.99 \\
Postmenstrual age & 0.001 & 0.97 \\
Heart rate & 0.001 & 0.116 \\
\hline
\end{tabular}

Groups: VLBW premature infants at $7 \mathrm{wk}$ or controls; dependent variable: DC. $r^{2}=71 \%$.

of left ventricle SV and abdominal aortic cross-sectional areas. The evaluation of WBAC is based on the Windkessel function of systemic circulation. Although the limitations of this model have been debated, its applicability has been widely demonstrated in vivo in humans (24-26). According to Chemla et al. (21). SV/PP gives a reliable estimate of total arterial compliance estimated by the area method and has been widely used using noninvasive techniques (27). Finapress was used at the wrist to evaluate the aortic PP. Currently there are no other alternative methods that can provide noninvasive, continuous arterial blood pressure tracing in neonates. Although the use of the Finapress technique did not allow measurement of arterial pressure at sites other than the wrist, Finapress wrist pulse pressure has been shown to be close to aortic PP in neonates $(20,28)$. To reduce the PP amplification between central and peripheral circulation, the continuous tracing of arterial blood pressure was initially calibrated on brachial arterial pressure recorded by oscillometric method. Indeed, noninvasively measured brachial arterial pressure has been shown to be comparable with aortic pressure in neonates (29). Moreover, measurements were performed after checking for closure of the ductus arteriosus. The Doppler technique is a noninvasive and accurate method of determining ascending aortic blood flow in neonates and children (30). The DC has been used previously to evaluate the distensibility of the brachial artery, the common carotid artery, and abdominal aorta in adults with low intra- and interoperator variability $(22,31)$. In the present study, abdominal aorta cross-sectional areas were measured rather than diameters to limit errors from the use of ultrasonic B-mode images of the abdominal aorta.

In our study, premature infants have higher heart rates than controls, at birth and at equivalent postmenstrual ages. Previous studies have reported an increased heart rate associated with reduced heart rate variability in premature infants during the postnatal period (32). Although baroreflex sensitivity has been shown to increase with postnatal age in premature infants, it is still depressed when they reach the theoretical term (33). This notion may be related to a change in the balance between the sympathetic and parasympathetic nervous systems, with a diminished parasympathetic component of heart rate control in premature infants (34). Importantly, DC was independent on heart rate in the present study according to previous studies that have shown that increasing heart rate is not associated with any change in aortic stiffness, whereas it affects the timing of the reflected pressure wave, produced by changes in the absolute duration of systole (35-37).
Our study shows that both WBAC and abdominal aortic distensibility in VLBW premature infants are reduced as early as the 5th day of life. Mechanisms that underlie changes in arterial distensibility, whether functional or anatomic, including a possible vascular remodeling, are unknown. In the present study, changes in aortic distensibility and WBAC were similar, suggesting that alteration of the viscoelastic properties of conductance arteries may at least partially explain the changes observed in whole systemic arterial wall properties. As far as conductance arteries are concerned, it may be speculated that extracellular matrix components are involved (38). In VLBW premature infants, the aortic wall may not be allowed to fully mature, a notion in line with the deficit in elastin wall artery content observed in anatomic pieces of human immature aorta (39).

The trend toward a narrower abdominal aorta in VLBW premature infants at a postmenstrual age similar to controls may be related to a structural basis. Indeed, narrower abdominal aorta has been found in adolescent girls who were born prematurely. The authors suggested the possibility of halted aortic development after premature birth according to the premature birth-related cessation of placenta circulation (7). Moreover, in the present study, no umbilical artery catheter has been used in the abdominal aorta in VLBW premature infants.

Interestingly, in our study, both WBAC and abdominal aorta distensibility, contrary to $\mathrm{PP}$, remained lower in premature infants 7 wk after birth than in controls on the fifth day. These findings are consistent with the hypothesis put forth by Martyn and Greenwald (13) that an early failure to synthesize adequate amounts of elastin during a critical window in fetal life is impossible to compensate later and may trigger the later persistence of low arterial compliance. Observations in infants born with a single umbilical artery or in the donor infant in twin-twin transfusion syndrome confirm that structural adaptations in the wall of large arteries and their repercussions on elastic properties occur in response to an alteration in blood flow and that such adaptations persist for several years $(14,40)$. This hypothesis is supported by the inverse trend of pulse wave velocity, an indicator of the aortic stiffness, with gestational age in healthy young adult (16).

In our study, nine $(80 \%)$ preterm infants received a single course of antenatal betamethasone to accelerate fetal maturation. This proportion is representative of the currently observed ratio of antenatal steroid exposure of such patients. Postnatal cardiovascular effects of one course of antenatal betamethasone, especially on arterial compliance, are still incompletely known, although it has been shown that a single course of antenatal betamethasone does not affect the cardiac wall thicknesses and systolic function in VLBW premature infants (41). Future research should aim to clarify the postnatal vascular effects of antenatal betamethasone exposure.

Several studies showed an increased blood pressure in healthy adults who were born prematurely (2,4-7). Impaired arterial distensibility may pave the way to the development of hypertension in the long term. Indeed, increased aortic stiffness is known to be associated with both systemic hypertension and left ventricular hypertrophy, and reduced compliance 
of the aorta of premature infants may amplify arterial wall impairing that accompanies aging $(42,43)$. Further studies may focus on the long-term follow-up of the aortic elastic properties and the incidence of cardiovascular disease in this population.

\section{REFERENCES}

1. Barker DJ, Osmond C, Golding J, Kuh D, Wadsworth ME 1989 Growth in utero, blood pressure in childhood and adult life, and mortality from cardiovascular disease. BMJ 298:564-567

2. Irving RJ, Belton NR, Elton RA, Walker BR 2000 Adult cardiovascular risk factors in premature babies. Lancet 355:2135-2136

3. Hofman PL, Regan F, Jackson WE, Jefferies C, Knigh DB, Robinson EM, Cutfield WS 2004 Premature birth and later insulin Resistance. N Engl J Med 351:2179-2186

4. Siewert-Delle A, Ljungman S 1998 The impact of birth weight and gestational age on blood pressure in adult life: a population-based study of 49-year-old men. Am J Hypertens 11:946-953

5. Kistner A, Celsi G, Vanpee M, Jacobson SH 2000 Increased blood pressure but normal renal function in adult women born preterm. Pediatr Nephrol 15:215-220

6. Johansson S, Iliadou A, Bergvall N, Tuvemo T, Norman M, Cnattingius S 2005 Risk of high blood pressure among young men increases with the degree of immaturity at birth. Circulation 112:3430-3436

7. Bonamy AK, Bendito A, Martin H, Andolf E, Sedin G, Norman M 2005 Preterm birth contributes to increased vascular resistance and higher blood pressure in adolescent girls. Pediatr Res 58:845-849

8. Langley-Evans SC 1997 Intrauterine programming of hypertension by glucocorticoids. Life Sci 60:1213-1221

9. Battista MC, Oligny LL, St-Louis J, Brochu M 2002 Intrauterine growth restriction in rats is associated with hypertension and renal dysfunction in adulthood. Am J Physiol Endocrinol Metab 283:E124-E131

10. Brenner BM, Garcia DL, Anderson S 1988 Glomeruli and blood pressure. Less of one, more the other. Am J Hypertens 1:335-347

11. Leeson CP, Kattenhorn M, Morley R, Lucas A, Deanfield JE 2001 Impact of low birth weight and cardiovascular risk factors on endothelial function in early adult life. Circulation 103:1264-1268

12. Lurbe E, Torro MI, Carvajal E, Alvarez V, Redon J 2003 Birth weight impacts on wave reflections in children and adolescents. Hypertension 41:646-650

13. Martyn CN, Greenwald SE 1997 Impaired synthesis of elastin in walls of aorta and large conduit arteries during early development as an initiating event in pathogenesis of systemic hypertension. Lancet 350:953-955

14. Cheung YF, Taylor MJ, Fisk NM, Redington AN, Gardiner HM 2000 Fetal origins of reduced arterial distensibility in the donor twin in twin-twin transfusion syndrome. Lancet 355:1157-1158

15. Martyn CN, Barker DJ, Jespersen S, Greenwald S, Osmond C, Berry C 1995 Growth in utero, adult blood pressure, and arterial compliance. Br Heart J 73:116-121

16. Oren A, Vos LE, Bos WJ, Safar ME, Uiterwaal CS, Gorissen WH, Grobbee DE, Bots ML 2003 Gestational age and birth weight in relation to aortic stiffness in healthy young adults: two separate mechanisms? Am J Hypertens 16:76-79

17. Martin H, Gennser G, Norman M 2000 Impaired endothelial function and increased carotid stiffness in 9-year-old children with low birthweight. Circulation 102:2739_ 2744

18. Akira M, Yoshiyuki S 2006 Placental circulation, fetal growth, and stiffness of the abdominal aorta in newborn infants. J Pediatr 148:49-53

19. Singhal A, Cole TJ, Fewtrell M, Deanfield J, Lucas A 2004 Is lower early growth beneficial for long term cardiovascular health? Circulation 109:1108-1113

20. Drouin E, Gournay V, Calamel J, Mouzard A, Roze JC 1997 Feasibility of using finger arterial pressure in neonates. Arch Dis Child Fetal Neonatal Ed 77:F139-F140

21. Chemla D, Hebert JL, Coirault C, Zamani K, Suard I, Colin P, Lecarpentier Y 1998 Total arterial compliance estimated by stroke volume-to-aortic pulse pressure ratio in humans. Am J Physiol 274:H500-H505
22. Reneman RS, Hoeks AP 1995 Arterial distensibility and compliance in hypertension. Neth J Med 47:152-161

23. Bland JM, Altman DG 1986 Statistical methods for assessing agreement between two methods of clinical measurement. Lancet 1:307-310

24. Belz GG 1995 Elastic properties and Windkessel function of the human aorta. Cardiovasc Drugs Ther 9:73-83

25. Liu Z, Brin KP, Yin FC 1986 Estimation of total arterial compliance: an improved method and evaluation of current methods. Am J Physiol 251:H588-H600

26. Marcus RH, Korcarz C, McCray G, Neumann A, Murphy M, Borow K, Weinert L, Bednarz J, Gretler DD, Spencer KT 1994 Noninvasive method for determination of arterial compliance using Doppler echocardiography and subclavian pulse tracings. Validation and clinical application of a physiological model of the circulation. Circulation 89:2688-2699

27. Kass DA, Shapiro EP, Kawaguchi M, Capriotti AR, Scuteri A, deGroof RC, Lakatta EG 2001 Improved arterial compliance by a novel advanced glycation end-product crosslink breaker. Circulation 104:1464-1470

28. Andriessen P, Schoffelen RL, Berendsen RC, de Beer NA, Oei SG, Wijn PF, Blanco CE 2004 Non invasive assessment of blood pressure variability in preterm infants. Pediatr Res 55:220-223

29. Colan SD, Fujii A, Borow KM, MacPherson D, Sanders SP 1983 Noninvasive determination of systolic, diastolic and end-systolic blood pressure in neonates, infants and young children: Comparison with central aortic pressure measurements. Am J Cardiol 52:867-870

30. Alverson DC, Eldrige M, Dillon T, Yabek SM, Berman W 1982 Noninvasive pulsed Doppler determination of cardiac output in neonates and children. J Pediatr 101:46-50

31. Rossi P, Tauzin L, Boussuges A, Frances Y 2004 Conventional ultrasonography Doppler in the assessment of arterial peripheral circulation. Rev Med Interne 25:135-140

32. Chatow U, Davidson S, Reichman BL, Akselrod S 1995 Development and maturation of the autonomic nervous system in premature and full-term infants using spectral analysis of heart rate fluctuations. Pediatr Res 37:294-302

33. Gournay V, Drouin E, Roze JC 2002 Development of baroreflex control of heart rate in preterm and full term infants. Arch Dis Child Fetal Neonatal 86:F151-F154

34. Eiselt M, Curzi-Dascalova L, Clairambault J, Kauffmann F, Medigue C, Peirano P 1993 Heart-rate variability in low-risk prematurely born infants reaching normal term: a comparison with full-term newborns. Early Hum Dev 32:183-195

35. Wilkinson IB, Mohammad NH, Tyrrell S, Hall IR, Webb DJ, Paul VE, Levy T, Cockcroft JR 2002 Heart rate dependency of pulse pressure amplification and arterial stiffness. Am J Hypertens 15:24-30

36. Nichols WW, Conti R, Walker WE, Milnor WR 1977 Input impedance of the systemic circulation in man. Circ Res 40:451-458

37. Albaladejo P, Copie X, Boutouyrie P, Laloux B, Descorps Déclère A, Smulyan H, Bénétos A 2001 Heart rate, arterial stiffness, and wave reflections in paced patients. Hypertension 38:949-952

38. Dobrin PB 1978 Mechanical properties of arteries. Physiol Rev 58:397-460

39. Berry CL, Looker T, Germain J 1972 Nucleic acid and scleroprotein content of the developing human aorta. J Pathol 108:265-274

40. Meyer WW, Lind J 1974 Iliac arteries in children with single umbilical artery. Structure, calcifications, and early atherosclerotic lesions. Arch Dis Child 49:671679

41. Vural M, Yilmaz I, Oztunc F, Illikkan B, Erginoz E, Perk Y 2005 Cardiac effects of a single course of antenatal betamethasone in preterm infants. Arch Dis Child Fetal Neonatal Ed 91:F118-F122

42. Cattell MA, Anderson JC, Hasleton PS 1996 Age-related changes in amounts and concentrations of collagen and elastin in normotensive human thoracic aorta. Clin Chim Acta 245:73-84

43. Mitchell GF, Parise H, Benjamin EJ, Larson MG, Keyes MJ, Vita JA, Vasan RS, Levy D 2004 Changes in arterial stiffness and wave reflection with advancing age in healthy men and women: the Framingham Heart Study. Hypertension 43:12391245 